Weed Technology

www.cambridge.org/wet

\section{Research Article}

Cite this article: Kennedy HJ, Fennimore SA, Slaughter DC, Nguyen TT, Vuong VL, Raja R, Smith RF (2020) Crop signal markers facilitate crop detection and weed removal from lettuce and tomato by an intelligent cultivator. Weed Technol. 34: 342-350. doi: 10.1017/

wet.2019.120

Received: 27 July 2019

Revised: 24 October 2019

Accepted: 6 November 2019

First published online: 14 November 2019

\section{Associate Editor:}

Michael Walsh, University of Sydney

\section{Nomenclature:}

lettuce, Lactuca sativa L.; tomato, Solanum lycopersicum L

\section{Keywords:}

crop marking; intelligent cultivation; robotic weeding; vegetable crops; weed-crop differentiation

\section{Author for correspondence:}

Steve Fennimore, University of California, Davis, Department of Plant Sciences, 1636 East Alisal, Salinas, CA 93905

Email: safennimore@ucdavis.edu

\title{
Crop signal markers facilitate crop detection and weed removal from lettuce and tomato by an intelligent cultivator
}

\author{
HannahJoy Kennedy ${ }^{1}$, Steven A. Fennimore ${ }^{1}$ (D) David C. Slaughter ${ }^{2}$, \\ Thuy T. Nguyen ${ }^{2}$, Vivian L. Vuong ${ }^{2}$, Rekha Raja² and Richard F. Smith ${ }^{3}$
}

${ }^{1}$ Fomer Graduate Student and Extension Specialist, Department of Plant Sciences, University of California, Davis, Salinas, CA, USA; ${ }^{2}$ Professor, former Graduate Student and Postdoctoral Scholar, Biological and Agricultural Engineering Department, University of California, Davis, CA, USA and ${ }^{3} \mathrm{Farm}$ Advisor, University of California Cooperative Extension, Salinas, CA, USA

\begin{abstract}
Increasing weed control costs and limited herbicide options threaten vegetable crop profitability. Traditional interrow mechanical cultivation is very effective at removing weeds between crop rows. However, weed control within the crop rows is necessary to establish the crop and prevent yield loss. Currently, many vegetable crops require hand weeding to remove weeds within the row that remain after traditional cultivation and herbicide use. Intelligent cultivators have come into commercial use to remove intrarow weeds and reduce cost of hand weeding. Intelligent cultivators currently on the market such as the Robovator, use pattern recognition to detect the crop row. These cultivators do not differentiate crops and weeds and do not work well among high weed populations. One approach to differentiate weeds is to place a machine-detectable mark or signal on the crop (i.e., the crop has the mark and the weed does not), thereby facilitating weed/crop differentiation. Lettuce and tomato plants were marked with labels and topical markers, then cultivated with an intelligent cultivator programmed to identify the markers. Results from field trials in marked tomato and lettuce found that the intelligent cultivator removed $90 \%$ more weeds from tomato and $66 \%$ more weeds from lettuce than standard cultivators without reducing yields. Accurate crop and weed differentiation described here resulted in a $45 \%$ to $48 \%$ reduction in hand-weeding time per hectare.
\end{abstract}

(c) The Author(s), 2019. Published by Cambridge University Press on behalf of Weed Science Society of America. This is an Open Access article, distributed under the terms of the Creative Commons Attribution licence (http:// creativecommons.org/licenses/by/4.0/), which permits unrestricted re-use, distribution, and reproduction in any medium, provided the original work is properly cited.

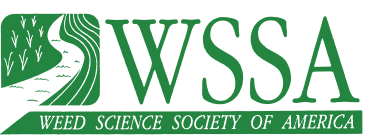

\section{Introduction}

High-value specialty crops are a majority of agricultural production in California. Specialty crops represent $61 \%$ of California's $\$ 46$ billion agricultural industry (CDFA 2017). Lettuce production in the United States covers 118,000 ha, primarily in Arizona and California, and tomato is produced on 134,000 ha primarily in California and Florida, with lesser production in numerous other states (USDA-NASS 2019). However, in the past $30 \mathrm{yr}$ very few herbicides have been developed for vegetable crops, and the available herbicides generally control only a fraction of weed species that are present (Fennimore et al. 2010; Fennimore and Doohan 2008; Lati et al. 2016; Van der Weide et al. 2008).

Weeds are difficult to control in lettuce and tomato due to labor shortages, increasing costs of hand weeding, and limited herbicide options (Fennimore and Cutulle 2019). Lettuce must meet industry standards of size and shape and have visual appeal to the consumer (Kader et al. 1973). Lettuce is very sensitive to weed competition, which can result in poor-quality produce (Fennimore and Umeda 2003). There is no tolerance for contamination of bagged lettuce salad mixes with weed plant parts; and therefore, weeds must be controlled if lettuce is to be harvested (Fennimore et al. 2010; Lati et al. 2016; Slaughter et al. 2008a). Weeds can also be hosts to insects and pathogens that can infest crops (Fennimore et al. 2014; Lati et al. 2016; Lechenet et al. 2017; Slaughter et al. 2008a).

Organic crops of all types are in need of additional weed control tools (Fennimore and Doohan 2008) because the nonselective contact herbicides available for use with organic crops are not widely used because they can be much more expensive and much less efficacious than other weed-control methods such as propane flaming or tillage (Boyd et al. 2006; Gramig et al. 2018; Melander et al. 2015; Pérez-Ruíz et al. 2014). Consequently, mechanical weed control is an important part of weed management in conventional and organic vegetable crops. Traditional interrow cultivation, however, only removes weeds between crop rows and leaves the weeds within the crop row (Lati et al. 2016; Melander et al. 2015, 2017). The removal of in-row weeds requires hand weeding, a tedious, time-consuming, and expensive process (Fennimore and Doohan 2008; Lati et al. 2016; Pérez-Ruíz et al. 2014; Rasmussen et al. 2012; Van der Weide et al. 2008). 


\section{Vegetable Weed Control Costs}

Weed control costs for conventional head lettuce production in California are estimated at $\$ 533$ to $\$ 788 \mathrm{ha}^{-1}$ (Tourte et al. $2015,2017)$, whereas weed control costs in organic leaf lettuce is $\$ 1,208 \mathrm{ha}^{-1}$ (Tourte et al. 2009) at current labor rates. Weed control costs in processing tomatoes are about $\$ 556 \mathrm{ha}^{-1}$ or $12 \%$ of production costs (Miyao et al. 2017). Additionally, hand-weeding costs have increased due to labor shortages, changes in California overtime regulations, higher minimum wages since 2015, and decreased labor immigration from Mexico (Tourte et al. 2017; Zahniser et al. 2018). The result is greater vulnerability of growers to crop losses due to weeds.

Automation of weed removal may be a method to reduce weed control costs in vegetable crops. Intelligent intrarow cultivators (ICs) provide an alternate weed management option to standard interrow cultivation. Previous results have shown that IC can reduce the need for hand weeding compared to standard cultivators (Lati et al. 2016) and may reduce weed control costs. The Robovator cultivator evaluated by Lati et al. (2016) relied on pattern recognition of the rows and crop plants within the rows based on the expected crop spacing within the rows. This machine cannot differentiate between crops and weeds and requires a size difference between crops and weeds and a low to moderate weed population to function accurately. Where weeds and crops are similar in size and weed densities are high, the efficacy of the Robovator is reduced (Lati et al. 2016).

\section{Intelligent Cultivators}

Selective weed removal without damage to the crop is the objective of IC systems (Fennimore and Cutulle 2019). Intelligent intrarow cultivation requires three technologies: a machine-vision system that detects crop plants and weeds; an image classification and decision algorithm that differentiates between crop plants and weeds; and control over the actuator that targets the weed while protecting the crop (Christensen et al. 2009; Slaughter et al. 2008a, 2008b). Precision guidance systems, decision algorithms, and precision in-row weed control devices are commercially available or are at an advanced level of development (Christensen et al. 2009; Fennimore et al. 2016; Slaughter et al. 2008a, 2008b). Accurate crop detection and differentiation from weeds, at real-time speeds, would allow for greatly improved intrarow cultivation (Fennimore et al. 2016; Slaughter et al. 2008b).

\section{Weed-Crop Differentiation}

The main challenge for IC is to differentiate between crops and weeds using digital imagery and processing at field operation speeds of at least $0.45 \mathrm{~m} \mathrm{~s}^{-1}$. Researchers have tested various methods to differentiate crops from weeds based on plant characteristics such as color, reflectance, leaf or plant shape, leaf or plant texture, leaf or plant size, or size differential (i.e., a transplanted crop plant will be much larger than a recently emerged weed; Lati et al. 2016; Slaughter et al. 2008b). However, these techniques are currently not reliable for commercial implementation due to a lack of accuracy or slow processing speeds. Detailed descriptions of various weed and crop differentiation techniques such as GPS guidance, electromagnetic absorbance, and machine vision are provided by Fennimore et al. (2016). A new method of crop and weed differentiation called "plant signaling" is presented by Raja et al. (2019a). The plant signaling concept has been used with machine vision in the field of automated weed control for real-time differentiation between crop plants and weeds (Raja et al.

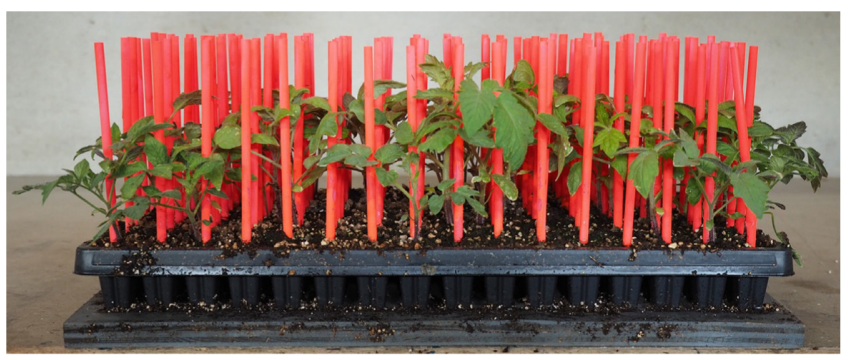

Figure 1. Plant labels in tray of tomato seedlings prior to transplanting. The labels and tomato plants were transplanted together in the field.

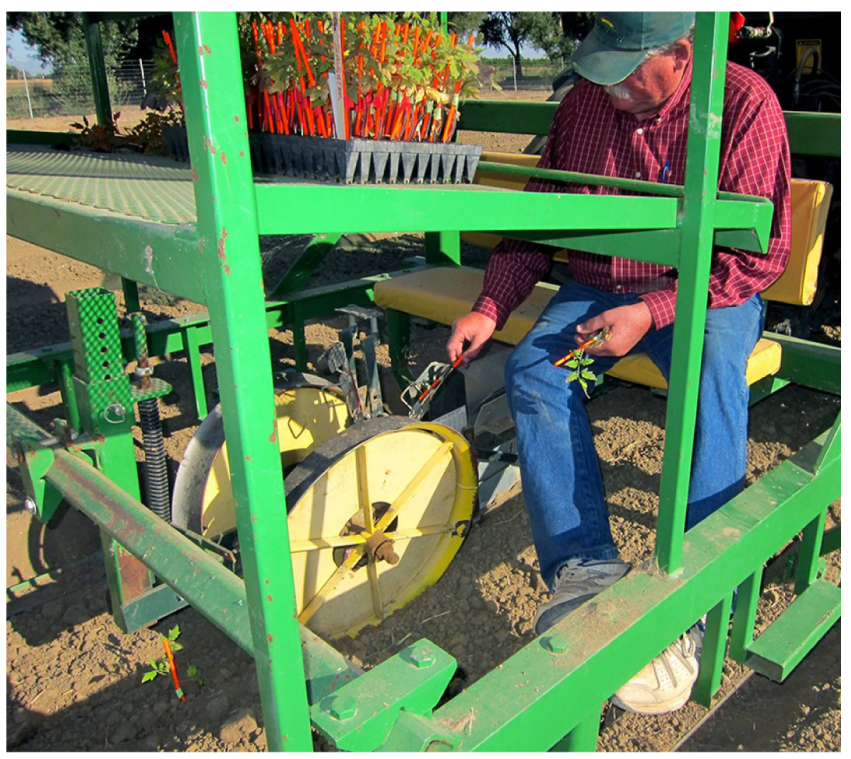

Figure 2. Holland transplanter with butterfly transfer fingers used for transplanting plant labels and tomatoes together.

$2019 b, 2019 c)$. It is based on the premise that the identity of the crop is known with certainty when it is planted, whether transplanted or seeded. Thus, if the crop has a machine-readable signal, then the IC would recognize the signal and protect the crop. Plants without the signal (i.e., weeds) would not be protected and would be removed by the IC. The objective of this work was to test a crop signaling system for crop detection accuracy and weed control efficacy by an IC in lettuce and tomato.

\section{Materials and Methods}

\section{Marking System Descriptions}

Two methods of plant signaling were considered: physical plant labels and topical markers. Biodegradable beverage straws made from polylactic acid or "corn plastic" were used as the physical plant labels in this study (item code EPST910, Eco Products, 4755 Walnut Street, Boulder, CO; https://www.ecoproducts.com/compostable_ straws.html; Figure 1). The straws were $24 \mathrm{~cm}$ long, $8 \mathrm{~mm}$ in diameter, and clear in color. The straws were painted with either green or orange fluorescent water-based paint (Precision line marking paint, product numbers 203032 and 203036, Rust-oleum ${ }^{\circledR}, 11$ E. Hawthorn Pkwy, Vernon Hills, IL; https://www.zoro.com/rust-oleumlinemarking-paint-17-oz-fl-green-203032/i/G3270617/\#description). The painted straws were then placed next to tomato seedlings in the planting trays and then planted together (Figure 2). 

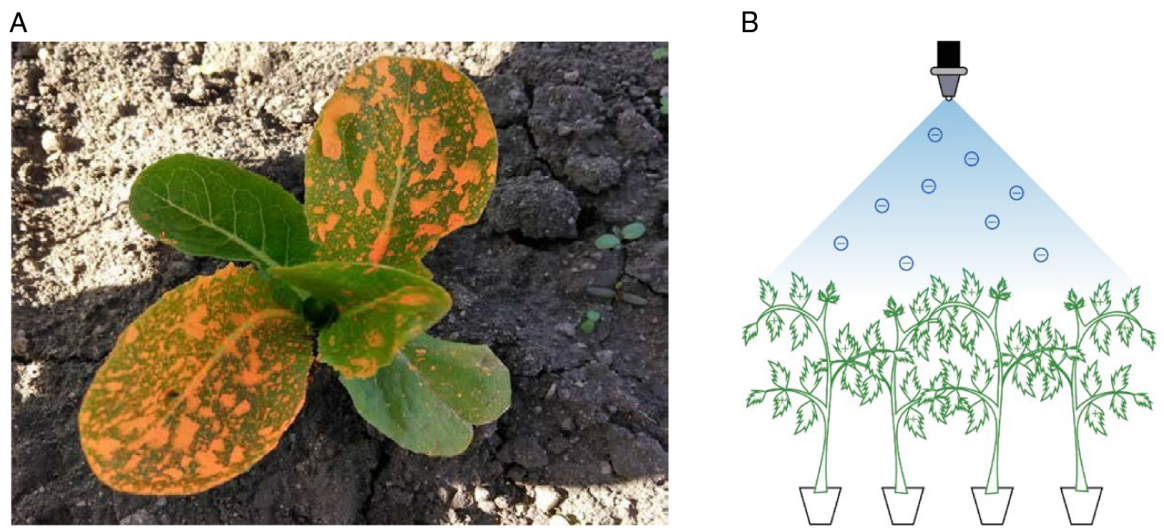

Figure 3. (A) Topical marker on lettuce plants. (B) Spray application of topical marker on crop plants.

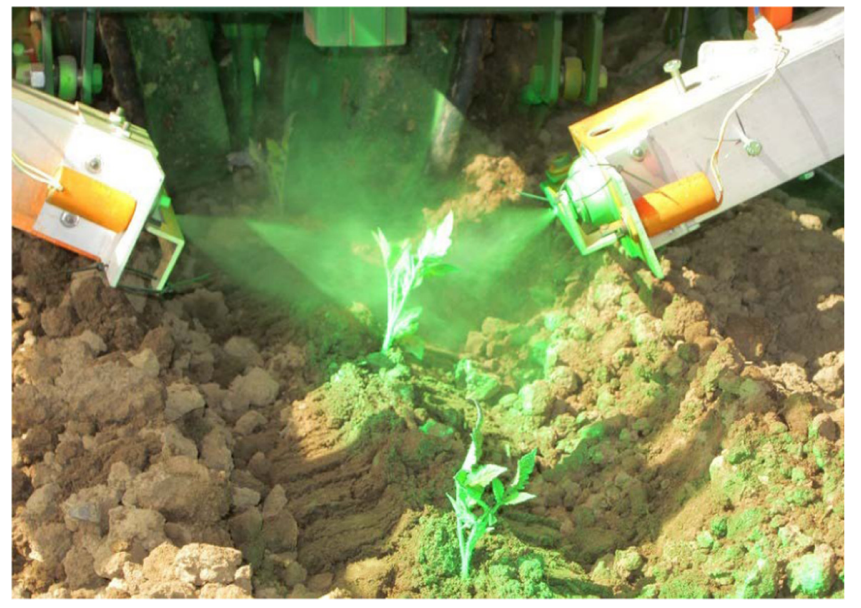

Figure 4. Topical marker sprayed on tomato transplants by applicator mounted on the transplanter during the process of transplanting.

The topical marker used on plant foliage was green or orange fluorescent water-based paint (Wildfire Visible Luminescent Paint, Wildfire Inc., Venice, CA; Figure 3A and B), diluted with water to $45 \%$ to $50 \%$ concentration. A foliar spray system was used to apply the topical marker to lettuce foliage and tomato seedlings prior to planting while they were in trays (Figures 3A and $\mathrm{B}$ ). An alternative method was also used in which a spray system was mounted on the transplanter to mark the tomato plants as they were transplanted (Figure 4).

\section{Intelligent Cultivator}

The IC used in this research was developed at the University of California-Davis (Raja et al. 2019a). It uses a machine vision system to detect physical labels and topical markers on the crop. The mechanical cultivator knives open to avoid the marked crop plants and close to uproot weeds in the intrarow space.

The machine vision system consists of a camera, six mirrors, and ultraviolet (UV) light-emitting diodes (LEDs; Slaughter et al. 2019; Figure 5). The color digital camera used was a single lens electronically controlled with a high-resolution scan sensor (Model Scout scA1600 gm/gc, Basler Inc., Ahrensburg, Germany). The mirrors are first-surface mirrors (Model 0.485 Thickness in Glass Sheets, Kaleidoscopes Inc., Clermont, IA). The two sets of six high-efficacy UV LEDs (Model LZ4-00UA00

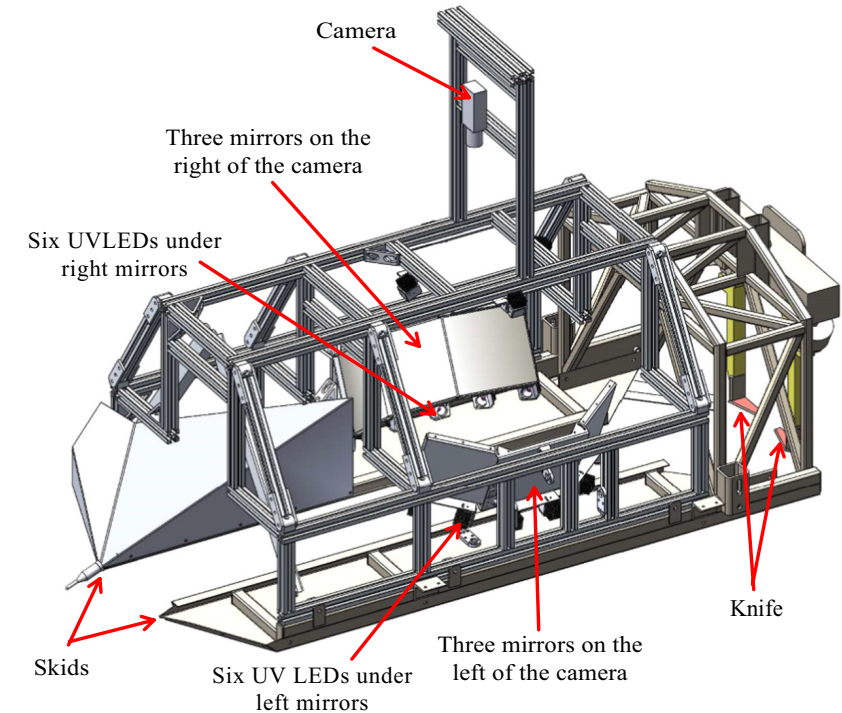

Figure 5. Frame of the weed knife control system, including a camera mounted on top, 6 first-surface mirrors, 12 ultraviolet light-emitting diodes, and an air-based mechanical cultivator knife (Slaughter et al. 2019).

Ultraviolet $410 \mathrm{~nm} 10$ Watt, LED Engin Inc., San Jose, CA) have LED lighting reflectors (Model C10437 Boomerang Hexagonal, Ledil Oy, Finland). The camera, capturing images with resolution of $1,624 \times 1,230$ pixels, was equipped with a fixed focal-length lens (Model Computer M0814-MP2 8 mm 1:2.4 2/3-inch, CBC Group Inc., Tokyo, Japan) and was positioned at a proper height from the ground to capture the plant images on the mirrors. The two sets of mirrors were mounted on the left and right sides of travel direction, where each set had three $15-\times 10-\mathrm{cm}$ mirrors directed to three different view angles surrounding the target plant (Figure 6).

The mirror pairs of top-left and bottom-right mirrors (represented by yellow square-dot lines in Figure 6), middle-left and middle-right mirrors (represented by red solid lines), and bottom-left and top-right mirrors (represented by green dash-dot lines) were set up parallel to each other. This permitted estimation of the location of the plant signal despite visual occlusion from some angles (Slaughter et al. 2019).

The 12 UV LEDs were mounted below the mirrors and used to illuminate the plants from the sides. The high-intensity, controlled illumination system was developed to be capable of activating the unique fluorescent and reflectance characteristics of the plant 

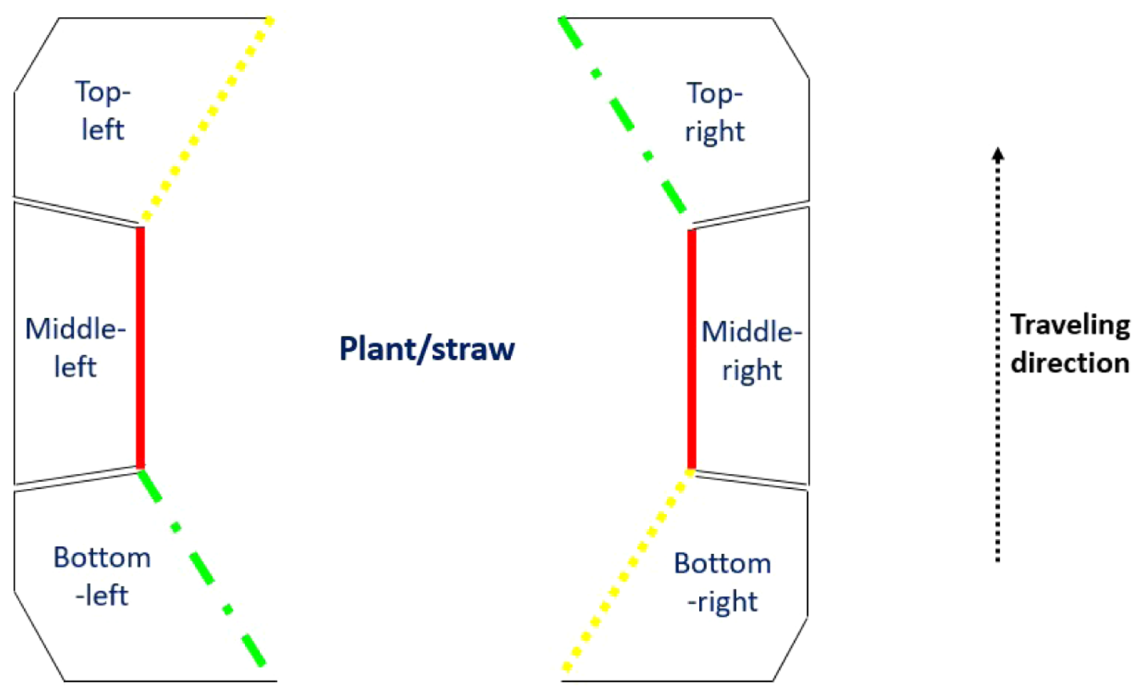

Figure 6. Layout from top view of six mirrors to support side views of the target plant. Top-left and bottom-right mirrors are set up parallel to each other, represented by the yellow square-dot lines. Middle-left and middle-right mirrors are set up parallel to each other, represented by the red solid lines. Bottom-left and top-right are set up parallel to each other, represented by the green dash-dot lines (Slaughter et al. 2019).
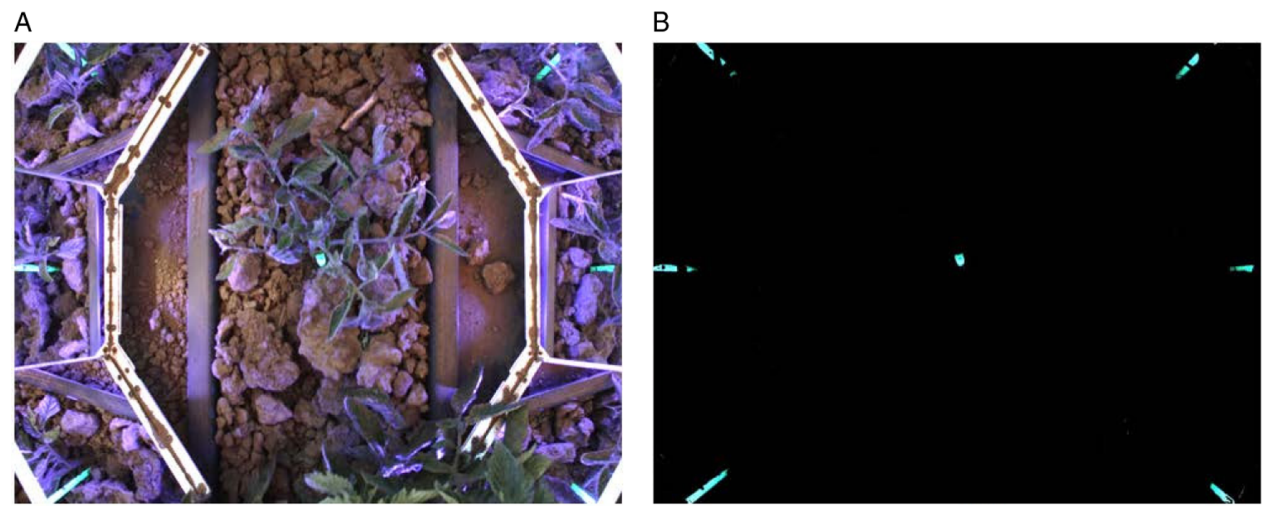

Figure 7. Image of a tomato plant with a green label taken (A) under normal light plus ultraviolet (UV) light and (B) under UV light only. Note the reflections of the green label in the six mirrors, and the actual label in the center of the image.

signals (Slaughter et al. 2019). The LED brightness was controlled by an adjustable power supply (Model HLG-185H-C1050B, MEAN WELL Enterprises Co., Guangzhou, China). A tomato plant with plant label (green straw) captured under direct sunlight in combination with UV light and under 100\% UV light demonstrates the method used for fluorescent imaging (Figure 7A and B). The imaging chamber was designed to be dark when skids are set on the soil surface to minimize the effects of sunlight from outside.

The knife blades were placed behind the imaging chamber to cut at a soil depth of approximately $2 \mathrm{~cm}$. Each knife blade (red parts in Figure 8) was made from a 6.4-mm-thick plate of hardened tool steel (Model Aristocrat D-2, air hardened to Rockwell 60, Precision Marshall Steel, Washington, PA) and cut into a triangular shape, with a triangle base width of $7 \mathrm{~cm}$ and a triangle height of $3.2 \mathrm{~cm}$.

The cutting edge was created by sharpening the two forward pointing sides of the triangular plate. Two arms (yellow parts in Figure 8) were used to fasten the knife blades at their bottom, with the triangular blade tip and sharpened cutting edges facing the forward travel direction. A pair of double-acting pneumatic cylinders (Model CCD15-SBP-004, Ingersoll Rand plc, Dublin, Ireland) control the cultivator knives. An electronically actuated solenoid air control valve (Model A212SD-024-D, Ingersoll Rand plc) was used to control knife motion with air pressure through the pneumatic cylinders.

The solenoid received open/close signals based on the detection results obtained using the camera. A field-programmable gate array-based real-time controller (Model NI CompactRIO-9014, National Instruments Corporation, Austin, TX) was used to control the knife via a digital I/O module (Model NI 9403 5V/TTL Bidirectional Digital I/O 32-channel Module, National Instruments Corporation). A wheel encoder (Model 63RS64 Polarized connection, Grayhill Inc., La Grange, IL, USA) was connected via a digital input module (Model NI $9411 \pm 5$ to 24 V Differential Digital Input 6-channel Module, National Instruments Corporation) to determine the location of the weed control system with respect to travel direction and to interpret the relative distance between the knife and the crop detection signal.

LabVIEW (National Instruments Corporation) code was used for implementation of camera image acquisition, object detection, and wheel encoder read and knife control. A fluorescent image of the field was electronically captured in real time using the camera under UV illumination to find the crop signal. Camera exposure time was set to $4 \mathrm{~ms}$ to capture sufficient image intensity from 
Table 1. Location, year, crop, crop signal method, and planting, with cultivation, hand-weeding, and harvest dates for tomato and romaine lettuce intelligent cultivator trials conducted at USDA research station and commercial field $\left({ }^{*}\right)$ in Salinas, CA, and at the field research station at Davis, CA.

\begin{tabular}{|c|c|c|c|c|c|c|c|c|c|c|c|}
\hline Trial & Location & Year & Crop & Crop signal & Seeding & $\begin{array}{l}\text { Transplanting/ } \\
\text { Thinning }\end{array}$ & Precounts taken & Cultivation & Postcounts taken & Hand Weeding & Harvest \\
\hline 1 & Davis & 2016 & Tomato & Physical & Mar 1 & Apr. 29 & May 24 & May 24 & May 24 & & - \\
\hline 2 & Salinas & 2016 & Lettuce & Physical & Jun 27 & - & Jul 22 & Jul 23 & Jul 25 & Jul 25 & - \\
\hline 3 & Salinas & 2016 & Lettuce & Topical & - & Sep 14 & Sep 21 & Sep 23 & Sep 27 & Sep 27 & - \\
\hline 4 & Davis & 2017 & Tomato & Topical & Mar 1 & Apr 28 & May 26 & May 26 & May 27 & May 30 & - \\
\hline 5 & Davis & 2017 & Tomato & Physical & Mar 1 & May 5 & Jun 1 & Jun 2 & Jun 4 & Jun 6 & Sep 6 \\
\hline 6 & Davis & 2017 & Tomato & Topical & Mar 1 & May 12 & Jun 8 & Jun 9 & Jun 12 & Jun 15 & - \\
\hline 7 & Davis & 2017 & Tomato & Topical & Mar 1 & May 12 & Jun 8 & Jun 9 & Jun 12 & Jun 15 & - \\
\hline 8 & Davis & 2017 & Tomato & Physical & Jul 1 & Aug 1 & Aug 17 & Aug 18 & Aug 24 & Aug 24 & - \\
\hline 9 & Salinas & 2017 & Lettuce & Physical & Jun 5 & Jun 21 & Jul 7 & Jul 7 & Jul 10 & Jul 10 & Aug 18 \\
\hline 10 & Salinas & 2017 & Lettuce & Physical & Jun 12 & Jul 11 & Jul 19 & Jul 20 & Jul 21 & Jul 24 & Aug 25 \\
\hline 11 & Salinas & 2017 & Lettuce & Physical & Jun 27 & Jul 18 & Jul 26 & Jul 27 & Jul 28 & Jul 28 & Sep 8 \\
\hline 12 & Davis & 2018 & Tomato & Topical & Mar 1 & Apr 25 & May 15 & May 18 & May 19 & May 21 & Aug 22 \\
\hline 13 & Davis & 2018 & Tomato & Topical & Mar 7 & May 2 & May 23 & May 24 & May 25 & May 28 & - \\
\hline 14 & Salinas ${ }^{\star}$ & 2018 & Lettuce & Physical & May 3 & May 29 & Jun 7 & Jun 8 & Jun 8 & Jun 8 & - \\
\hline
\end{tabular}
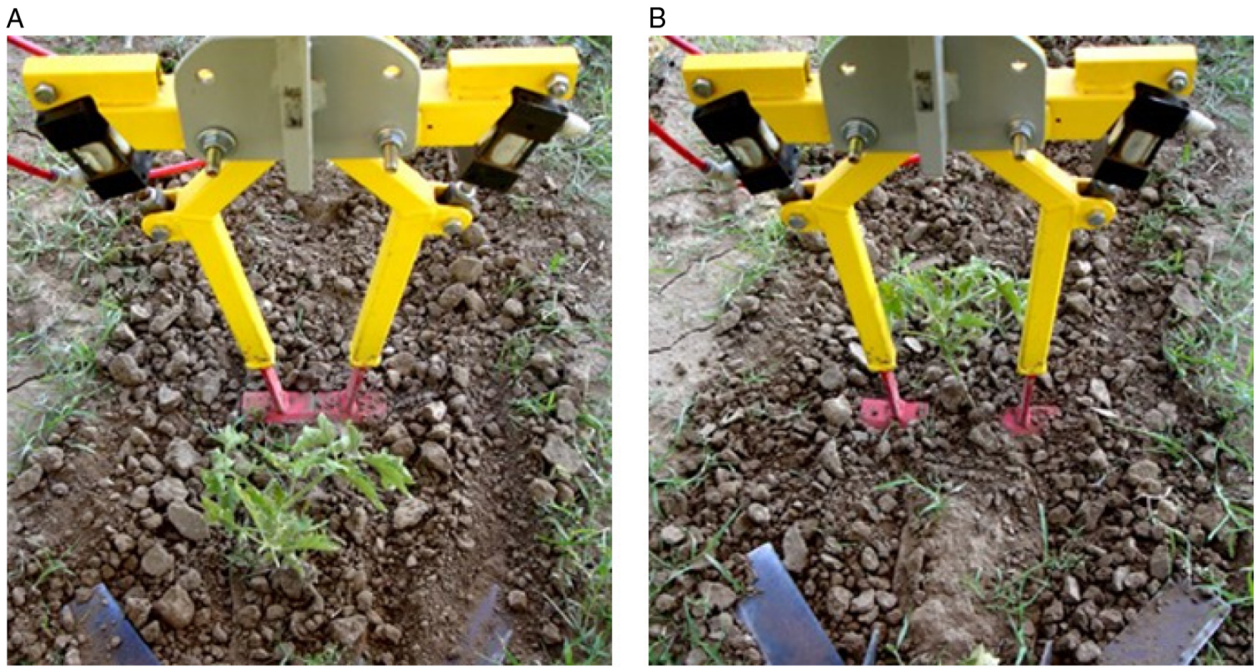

Figure 8. The actuator device used in this project. (A) Weed knives closed - uprooting weeds in crop row. (B) Weed knives open avoiding tomato plant.

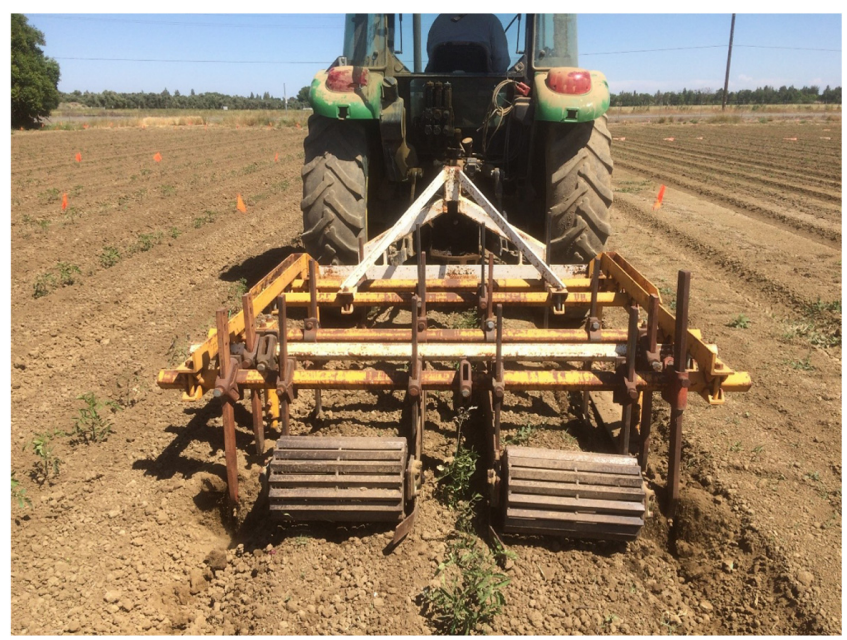

Figure 9. Standard cultivator setup for tomatoes, which left a $15-\mathrm{cm}$ noncultivated band on the crop row.

the 10-watt UV LEDs and to compensate for motion blur from the moving sled. The camera parameters, including focal length, focus, and aperture were manually set to achieve the best quality images at the tractor speed of $3.2 \mathrm{~km} \mathrm{hr}^{-1}$. Once a fluorescent plant signal was detected, LabVIEW software algorithms determined plant timing to open (Figure 8A shows the knives open) and closed (Figure 8B; Slaughter et al., 2019) as the cultivator knives remove weeds around tomato plants.

\section{Field Trials}

Eight field trials in tomato and six in lettuce were conducted between 2016 and 2018 (Table 1). Eight trials were conducted using physical plant labels (Figure 1) next to the plants and six used a topical marker on the plants (Figures 3 and 4).

\section{Tomato}

Field trials in processing tomatoes were located on a silt loam soil on the University of California-Davis vegetable field crops research station near Davis, CA $\left(38.313590^{\circ} \mathrm{N},-121.46189^{\circ} \mathrm{W}\right)$. In 2016 and 2017 trials, the 'Halley $3155^{\prime}$ variety was used, whereas Trial 13 in 2018 used the 'HM 3887' variety, but due to a shortage of that variety, 'Halley 3155 ' was also used. The tomatoes were seeded in trays with Pro-Mix HP media and kept in a greenhouse for $45-60$ days until they were 20 - to $25-\mathrm{cm}$ tall. Tomatoes were transplanted into $1.5-\mathrm{m}$ beds at 38 - to $46-\mathrm{cm}$ spacing in a single center 
A

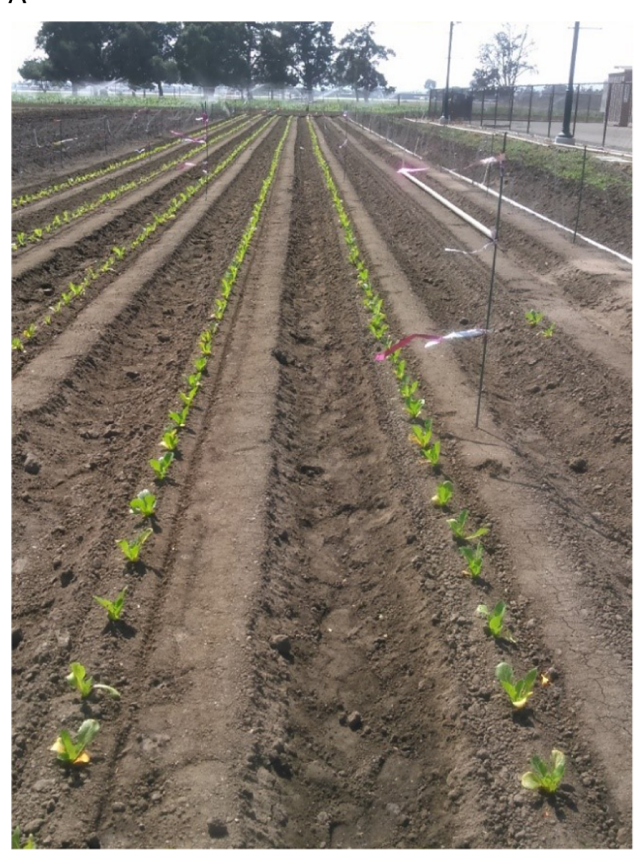

B

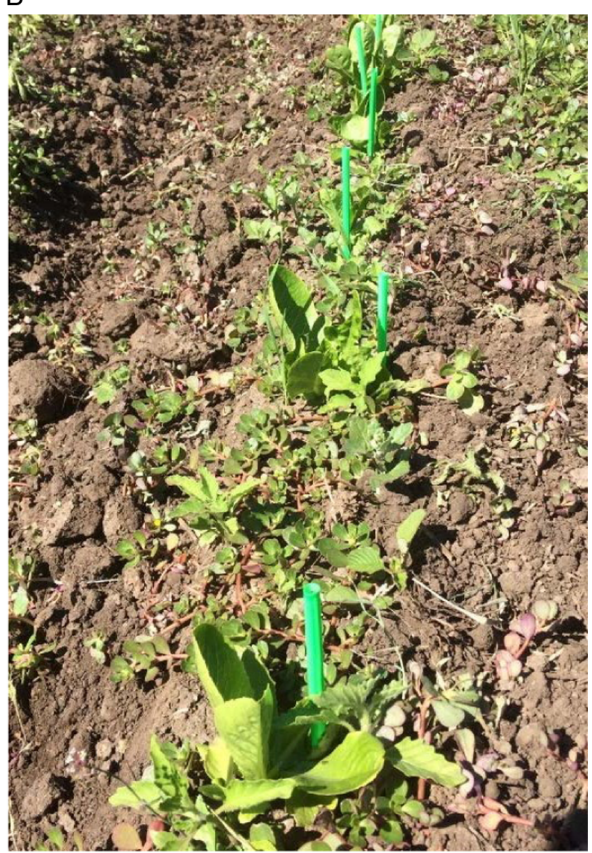

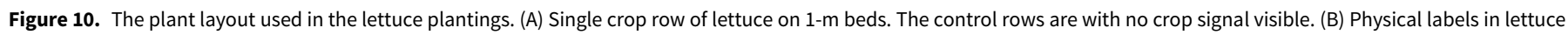
row 2 wk after transplanting.

row using a New Holland Transplanter (Holland, MI) with butterfly transfer fingers (Figure 2, Table 1). The plots were furrow irrigated at 1- to 2-wk intervals and no preplant nitrogen fertilizer was applied because the intent was not to hold the plants for harvest. Tomato Trials 5 and 13 were chosen to take to yield and were side dressed with $100 \mathrm{~kg} \mathrm{ha}^{-1}$ of $46-0-0$ fertilizer $4 \mathrm{wk}$ after transplanting. Plant labels were added to seedling trays prior to transplanting (Figure 1) or the topical marker was applied to trays of tomato seedlings as described above (Figure 4). At transplanting, standard practices were followed; the top of the tomato plug was placed $5-6 \mathrm{~cm}$ below the soil surface to maximize soil contact and minimize dehydration. Tomato transplants were marked with paint $10 \mathrm{~cm}$ above the soil line and spaced $30 \mathrm{~cm}$ apart in the row. About $3 \mathrm{wk}$ after planting, all plots were cultivated with a standard mechanical cultivator (Figure 9). The standard cultivator consisted of a tractor-mounted frame with angled top knives and squirrel cage rollers on the outside of the single plant row, coulters and curved sweep knives set on the bed shoulders, and cultivator sweeps set in the furrows. The standard cultivator left a $15-\mathrm{cm}$ noncultivated band centered on the crop row.

Weed densities by species were measured before and after cultivation in four 18-cm-wide (centered on crop row) by $6-\mathrm{m}$-long sample areas randomly placed along the length of the plots. The time required by a laborer to hand weed the 6-m sample areas was recorded. Tomato Trials 5 and 13 were maintained until harvest so that marketable yield data could be collected.

\section{Lettuce}

Field trials using Romaine lettuce (cv. 'Solid King') were conducted in a sandy loam soil at the U.S. Department of Agriculture research station in Salinas, CA $\left(36.40123^{\circ} \mathrm{N},-121.36165^{\circ} \mathrm{W}\right)$. Two field trials were conducted in July and September 2016. The July trial used plant labels and the September trial used plant markers. Three field trials were conducted during June to August of 2017. All three trials used plant markers. The three trials using Romaine lettuce were direct-seeded at 2-wk intervals during June and July 2017 in one crop row on standard 1-m beds (Figure 10A). Direct seeding was performed with a tractor-mounted Stanhay planter set at $5.7 \mathrm{~cm}$ in-line seed spacing. The plots received 6-20-20 fertilizer during bed formation at $336 \mathrm{~kg} \mathrm{ha}^{-1}$ and a side dress application of ammonium sulfate fertilizer 21-0-0-24 (S) at $336 \mathrm{~kg} \mathrm{ha}^{-1} 3 \mathrm{wk}$ after planting. Two weeks after emergence, the plots were thinned with a hoe to a 20 - to $25-\mathrm{cm}$ spacing. Physical labels were manually placed in the ground within $2.5 \mathrm{~cm}$ of the base of the plant (Figure 10B) prior to cultivation.

Six weeks after seeding, the entire experimental plot was cultivated with a standard mechanical cultivator. The standard cultivator used a tractor-mounted diamond tool bar with angled top knives and crust breaker set between plant rows, coulters and curved sweep knives set on the bed shoulders, and cultivator sweeps set in the furrows.

The standard cultivator left a $15-\mathrm{cm}$ noncultivated band centered on the crop row. The IC operated within $2 \mathrm{~cm}$ of the lettuce plants on all sides. Precultivation weed counts were measured the day before cultivation and postcultivation weed counts were taken the day after cultivation. Weed densities were measured in a $15-\mathrm{cm}$ band centered on the crop row in each of two 6-m samples in the field. A third sample area was added in the second and third trials. Weeds that were uprooted or had roots exposed were considered dead. After cultivation, hand weeding was performed and timed as described for the tomato trials. The time spent by a laborer to hand weed with a hoe was recorded.

The 2017 lettuce trials were maintained until commercial maturity and number of marketable heads and weight of marketable heads were recorded. The 2018 trial was conducted at a commercial lettuce field near Salinas, CA $\left(36.37502^{\circ} \mathrm{N},-121.35258^{\circ} \mathrm{W}\right)$ with direct-seeded iceberg lettuce (cv. 'Oso Flaco') on a silty clay soil. The lettuce was grown as described for the 2017 field trials. 


\section{Statistical Analysis}

The weed density and hand-weeding time data were normalized to account for different sizes of sample areas. The 2017 tomato trials (Trials 4-8) were replicated four times, but the replicates (i.e., rows) were placed side-by-side, thus the individual rows were analyzed as subsamples. All other trials were arranged in a randomized complete block with four replicates.

RStudio Version 1.1.383 (RStudio Inc., Boston, MA) was used for statistical analysis. Differences between pre- and postcultivation weed counts determined weed removal effectiveness. The most efficacious treatments removed the greatest proportion of weeds.

The difference in weed densities between pre- and postcultivation was analyzed using analysis of covariance to measure the effect of cultivator type on weed density. The precultivation weed count was the covariate. The assumptions of normality and homogeneity of variances were not met by the lettuce and tomato data, based on the Shapiro-Wilk test and Levine's test, so a natural log transformation was applied to the response variable based on model fit. The assumptions of normality and homogeneity of variances were not met by the lettuce data, based on the Shapiro-Wilk test and Levine's test, so a square root transformation was applied to the covariate and the response (postcultivation weed count) based on model fit. The model used was:

$$
\begin{aligned}
& \text { Postcultivation weed count }=\text { cultivation method } * \text { Trial No. } \\
& + \text { cultivation method }+ \text { Trial No. }+ \text { cultivation method } \\
& * \text { precultivation weed count } \\
& + \text { RANDOM EFFECT }(\text { experimental unit }) \\
& + \text { RANDOM EFFECT }(\text { row No. })
\end{aligned}
$$

ANOVA was performed on the hand-weeding time data to measure the effect of the cultivators. The assumption of homogeneity of variances was not met with the lettuce hand-weeding time data, based on Levine's test, so a natural log transformation was applied to the result (hand-weeding time). No transformation was applied to the lettuce and tomato hand-weeding time data because the assumption of homogeneity of variances was met according to Levine's test. The model used was:

$$
\begin{aligned}
& \text { Hand weed time }=\text { Cultivation method } * \text { Trial No. } \\
& + \text { Cultivation method }+ \text { Trial No. } \\
& + \text { RANDOM EFFECT }(\text { experimental unit }) \\
& + \text { RANDOM EFFECT }(\text { row No. })
\end{aligned}
$$

\begin{tabular}{|c|c|c|c|c|}
\hline \multicolumn{2}{|l|}{ Weed species } & 2016 & 2017 & 2018 \\
\hline & & \multicolumn{3}{|c|}{$\%$} \\
\hline Prostrate pigweed & Amaranthus blitoides S. Wats. & 0 & 50 & 0 \\
\hline Redroot pigweed & Amaranthus retroflexus $\mathrm{L}$. & 8 & 0 & 25 \\
\hline Yellow nutsedge & Cyperus esculentus L. & 0 & 14 & 0 \\
\hline Common purslane & Portulaca oleracea L. & 8 & 9 & 55 \\
\hline Common lambsquarters & Chenopodium album L. & 53 & 8 & 0 \\
\hline Black nightshade & Solanum nigrum L. & 16 & 6 & 10 \\
\hline Barnyardgrass & $\begin{array}{l}\text { Echinochloa crus-galli (L.) } \\
\text { P. Beauv. }\end{array}$ & 7 & 2 & 10 \\
\hline Hairy nightshade & Solanum physalifolium Rusby & 8 & 0 & 0 \\
\hline Yellow foxtail & $\begin{array}{l}\text { Setaria pumila (Poir.) } \\
\text { Roem. \& Schult. }\end{array}$ & 0 & 1 & 0 \\
\hline Field bin & Convolvulus arvensis L. & 0 & 1 & 0 \\
\hline Annual sowthistle & Sonchus oleraceus L. & 0 & 1 & 0 \\
\hline
\end{tabular}

Weights were determined for both lettuce and tomato yields, and in lettuce only the number of heads were also determined. The model used for yields was:

$$
\begin{aligned}
& \text { No. of heads or } \mathrm{kg} \mathrm{ha}^{-1}=\text { Cultivation method } * \text { Trial No. } \\
& + \text { Cultivation method }+ \text { Trial No. } \\
& + \text { RANDOM EFFECT }(\text { experimental unit }) \\
& + \text { RANDOM EFFECT (row No. })
\end{aligned}
$$

Table 2. Weed species proportion of total weed densities in the tomato trials at Davis, CA during 2016 to 2018.

Table 3. Weed species proportions in the lettuce trials over $3 \mathrm{yr}$ at Salinas, CA.

\begin{tabular}{llrrr}
\hline Weed species & & 2016 & 2017 & 2018 \\
\hline & & & & \\
Burning Nettle & Urtica urens L. & 5 & 5 & 0 \\
Common purslane & Portulaca oleracea L. & 0 & 65 & 80 \\
Hairy nightshade & Solanum physalifolium Rusby & 2 & 0 & 0 \\
Little mallow & Malva parviflora L. & 2 & 10 & 0 \\
Shepherd's-purse & Capsella bursa-pastoris (L.) Medik. & 0 & 0 & 20 \\
Volunteer rye & Secale cereale L. & 0 & 10 & 0 \\
Other & & 1 & 10 & 0 \\
\hline
\end{tabular}

The EMMEANS package in $\mathrm{R}$ was used to calculate the leastsquare means. Once analysis was complete, the results were back-transformed for presentation in the originals units.

\section{Results and Discussion}

The most common weeds present in the tomato trials were redroot pigweed (Amaranthus retroflexus L.), prostrate pigweed (Amaranthus blitoides S. Wats.), barnyardgrass [Echinocloa crus-galli (L.) Beauv.], black nightshade (Solanum nigrum L.), yellow nutsedge (Cyperus esculentus L.), common purslane (Portulaca oleracea L.), and common lambsquarters (Chenopodium album L.; Table 2). The primary weeds in the lettuce trials were burning nettle (Urtica urens L.) in 2016 and common purslane in 2017 and 2018 (Table 3). The weed sizes at the time of cultivation were 2 to $5 \mathrm{~cm}$ tall, and irrigation was timed so that soil was sufficiently dry for cultivation.

\section{Weed Control}

The IC was more effective than the standard cultivator at removing weeds from the interrow space. The treatment-by-trial interaction in the weed reduction model (Equation 1) was not significant so the data were pooled separately for tomato and lettuce. In tomato, 11.2 weeds $\mathrm{m}^{-2}$ remained after IC, while 113.2 weeds $\mathrm{m}^{-2}$ remained after standard cultivation. This is a $90 \%$ reduction in the number of weeds remaining after cultivation $(\mathrm{P}<0.05$, Table 4). In the lettuce trials, 18.0 weeds $\mathrm{m}^{-2}$ remained after intelligent cultivation, while 52.8 weeds $\mathrm{m}^{-2}$ remained after standard cultivation, which is a $66 \%$ reduction in weeds remaining after cultivation $(\mathrm{P}<0.05$, Table 4$)$. 
Table 4. Effect of cultivator type on in-row weed densities after cultivation, time to hand weed and marketable yield in tomatoes and lettuce.

\begin{tabular}{|c|c|c|c|c|c|}
\hline \multirow[t]{2}{*}{ Crop } & \multirow[t]{2}{*}{ Cultivator type } & \multirow{2}{*}{$\begin{array}{l}\text { Weeds remaining } \\
\text { after cultivation }{ }^{\mathrm{a}}\end{array}$} & \multirow{2}{*}{$\frac{\text { Time to hand weed }}{\mathrm{h} \mathrm{ha}^{-1}}$} & \multicolumn{2}{|c|}{ Marketable yield } \\
\hline & & & & $\mathrm{kg} \mathrm{ha}^{-1}$ & No. lettuce heads ha ${ }^{-1}$ \\
\hline Tomato $^{\mathrm{b}}$ & Intelligent & $11.2 \mathrm{a}$ & $19.2 \mathrm{a}$ & $49450.6 \mathrm{a}$ & - \\
\hline Tomato & Standard & $113.2 \mathrm{~b}$ & $36.8 \mathrm{~b}$ & $56379.7 \mathrm{a}$ & - \\
\hline Lettuce $^{c}$ & Intelligent & $18.0 \mathrm{a}$ & $39.6 \mathrm{a}$ & $45840.8 \mathrm{a}$ & $39153.2 \mathrm{a}$ \\
\hline Lettuce & Standard & $52.8 \mathrm{~b}$ & $72.0 \mathrm{~b}$ & $38045.8 \mathrm{a}$ & 36913.9 a \\
\hline
\end{tabular}

a Values in the same column with different letters are significantly different at the $5 \%$ level of probability according to the least-square means

method with Tukey's adjustment.

${ }^{b}$ All tomato trials for 2016-2018. Trials $1,4-8$, and 12-13 in Table 1.

cAll lettuce trials for 2016-2018. Trials 2-3, 9-11, and 14 in Table 1.

The treatment-by-trial interaction in the hand-weed time model (Equation 2) was not significant so the tomato data were pooled. Hand weeding in the tomato trials required $19.2 \mathrm{~h} \mathrm{ha}^{-1}$ following the IC, whereas the standard cultivator required $36.8 \mathrm{~h} \mathrm{ha}^{-1}$, which is a $48 \%$ reduction $(\mathrm{P}<0.05$, Table 4$)$. For lettuce, the treatment-by-trial term in the hand-weed time model (Equation 2) was not significant so the data were pooled (Table 4). Hand weeding of lettuce required $39.6 \mathrm{~h} \mathrm{ha}^{-1}$ following IC, whereas $72.0 \mathrm{~h} \mathrm{ha}^{-1}$ was required for the standard cultivator, a $45 \%$ reduction in time $(\mathrm{P}<0.05)$.

The time spent hand weeding after cultivation in tomato and lettuce were similar because the worker was walking the same distances in both crops whether weeding or not, even though the IC removed $90 \%$ of the weeds in tomato vs. $66 \%$ in lettuce. This is because the IC leaves a $2-\mathrm{cm}$ protection zone around the crop where any weeds are left due to proximity to the crop. There were about 91,000 lettuce plants ha ${ }^{-1}$ and about 17,000 tomato plants $\mathrm{ha}^{-1}$. Therefore, there were more lettuce plants for the IC to protect and hence more weeds survived cultivation in lettuce than in tomato. Even though the IC did not remove all the weeds it passed over, significant reductions in manual labor were achieved while maintaining effective weed control.

\section{Crop Yields}

There was no difference between the cultivators in their effect on tomato fruit yield in 2017 ( $\mathrm{P}>0.05$, Table 4 ). The 2018 tomato yields were analyzed for the 'HM 3887 ' tomato variety alone because there were three replicates of this variety in both the standard cultivator and IC treatments. Marketable fruit yields in the intelligent and standard cultivator treatments were $36,660 \mathrm{~kg} \mathrm{ha}^{-1}$ and $33,784 \mathrm{~kg} \mathrm{ha}^{-1}$, respectively $(\mathrm{P}>0.05)$. The treatment-by-trial interaction in the lettuce yield models was not significant so the data were pooled. Similarly, there were no differences between the cultivators in their effect on lettuce yields $(P>0.05$, Table 4$)$. Yield data were analyzed both as the number of marketable lettuce heads per hectare and fresh weights in kilograms per hectare.

\section{Weed-Crop Differentiation}

One of the biggest challenges for automated IC is to enable a computer and vision system to differentiate between crops and weeds at normal field travel speeds (Slaughter et al. 2008a, 2008b). The complexity of field conditions, including variable lighting and visual occlusion, continue to challenge machine learning (Rasmussen et al. 2012; Slaughter et al. 2008a), particularly at high weed densities.

There are four traditional methods of crop/weed recognition: morphology, spectral reflectance, visual texture, and spatial context (Slaughter et al. 2008a, Slaughter 2014). The main advantage of the plant signaling method described here compared to the traditional methods is that crop identification was performed in real time $(30 \mathrm{~Hz})$ with accuracies approaching $100 \%$ without the need to learn crop-specific features. Performance was good even in fields with high weed densities. Morphology, spectral reflectance, and texture can identify crops and weeds with accuracies of $>90 \%$ but only where weed densities are low. In addition, the speed of travel can be quite slow due to the computational intensity of some techniques. The commercially available IC "Robovator" uses spatial context to recognize the crop and can perform intrarow weeding at speeds of $0.45 \mathrm{~m} \mathrm{~s}^{-1}$ (Lati et al. 2016). However, spatial context requires a distinct crop pattern best found in a transplanted field where the crop is much larger than the weeds and the crop stand is consistent. Furthermore, when high weed densities obscure the twodimensional pattern, the intrarow weeding program does not work.

Although the plant signaling system is very accurate, the system tested here is not of commercial scale. For transplants, the signal marker can be placed on the plant nursery trays just before transport to the field. A physical plant label could be a tag placed on the plant either before or during transplanting. The label should be of biodegradable material so that it degrades within a single crop cycle, because contamination of harvested produce with plastic tags is unacceptable. The use of a topical marker is relatively easy to apply, but it would be preferable that the marker be invisible except at specific wavelengths based on grower preference for "normal” produce appearance (M. Zischke, personal communication). The signaling methods described here are for transplanted vegetables, not for seeded vegetables. Development of a signaling method based on seed treatment with a xylem mobile compound that can translocate from the roots to the foliage may be feasible using the methods described by Taylor and Salanenka (2012) and Yang et al. (2018). Rhodamine-B applied to bean seed translocated via the xylem from the bean seed coat where it was absorbed by the roots and into the stem and foliage, where it was detected with a 590-nm peak by a camera. The imaging system was able to discriminate between bean and burning nettle (Urtica urens L.; Su et al. 2019). A machine-readable systemic marker that moves from the seed coat into the crop foliage could function in the same way as the physical marking system used here. An ideal scenario would be a systemic marker that could be applied as a seed treatment so that use of a crop signal would not be limited to transplanted crops.

Two types of crop signals were tested: physical plant labels and topical markers. The methods have very low false positive error rates and the classification accuracy achieved for both techniques approached $100 \%$. The crop signaling technique appears to be effective in creating a reliable method for automatic detection of crop plants in vegetable fields with high weed densities. Crop signaling technology could facilitate development of automated weed control robots that are as accurate in crop/weed differentiation 
as human workers are. A recommendation for future work is to develop a commercially viable marking method that is machine readable yet does not contaminate harvested produce or the field soil and subsequent rotational crops. For transplanted stem crops like tomato, a biodegradable, machine-readable tag attached to each stem as the transplanter sets the plants needs to be evaluated. Lettuce will probably require a machine-readable label attached to the first true leaves or a machine-readable label on the fiber-coated plant plug as it is set in the soil as occurs with the Plant Tape ${ }^{\circledR}$ http:// www.planttape.com/ system of vegetable transplanting.

Regardless of the technology used to differentiate weeds among crops, development of intelligent weed removal technology has improved weed control programs for horticultural crops that continue to rely on old herbicides and hand weeding (Fennimore and Cutulle 2019). Automated weed removal technology is disruptive in that it shifts the locus of discovery from large agrochemical companies that rely on broad-acre crops for profitability, to small engineering companies that have lower overhead costs and greater flexibility to find profitable markets in small noncompetitive niche crops like vegetables.

Acknowledgments. Thanks to the U.S. Department of Agriculture-National Institute of Food and Agriculture Specialty Crop Research Initiative (USDANIFA-SCRI-004530), the California Tomato Research Institute, and the California Leafy Greens Research Program for financial support; and to Leland Neilson, Burt Vannucci, and John Rachuy of the University of California-Davis for technical assistance in conducting this research. No conflicts of interest have been declared.

\section{References}

Boyd NB, Brennan EB, Fennimore SA (2006) Stale seedbed techniques for organic vegetable production. Weed Technol 20:1052-1057

[CDFA] California Department of Food and Agriculture (2017) California Agricultural Statistics Review 2016-2017. pp 1-126 https://www.cdfa.ca. gov/Statistics/PDFs/2017-18AgReport.pdf Accessed July 17, 2019

Christensen S, Søgaard HT, Kudsk P, Nørremark M, Lund I, Nadimi ES, Jørgensen R (2009) Site-specific weed control technologies. Weed Res 49:233-241

Fennimore SA, Cutulle M (2019) Robotic weeders can improve weed control options for specialty crops. Pest Manag Sci 75:1767-1774

Fennimore SA, Doohan DJ (2008) The challenges of specialty crop weed control, future directions. Weed Technol 22:364-372

Fennimore SA, Smith RF, Tourte L, LeStrange M, Rachuy JS (2014) Evaluation and economics of a rotating cultivator in bok choy, celery, lettuce, and radicchio. Weed Technol 28:176-188

Fennimore SA, Slaughter DC, Siemens MC, Leon RG, Saber MN (2016) Technology for automation of weed control in specialty crops. Weed Technol 30:823-837

Fennimore SA, Tourte L, Rachuy JS, Smith RF, George C (2010) Evaluation and economics of a machine-vision guided cultivation program in broccoli and lettuce. Weed Technol 24:33-38

Fennimore SA, Umeda K (2003) Time of glyphosate application in glyphosatetolerant lettuce. Weed Technol 17:738-746

Gramig G (2018) Weed management in organic crop cultivation. Pages 319-334 in RL Zimdahl, ed. Integrated weed management for sustainable agriculture. 1st edn. Cambridge, UK: Burleigh Dodds Publishing

Kader AA, Lipton WL, Morris LL (1973) Systems for scoring quality of harvested lettuce. HortSci 8:408-409

Lati RN, Siemens MC, Rachuy JS, Fennimore SA (2016) Intrarow weed removal in broccoli and transplanted lettuce with an intelligent cultivator. Weed Technol 30:655-663

Lechenet M, Deytieux V, Antichi D, Aubertot J-N, Bàrberi P, Bertrand M, Cellier V, Charles R, Colnenne-David C, Dachbrodt-Saaydeh S, Debaeke P, Doré T, Farcy P, Fernandez-Quintanilla C, Grandeau G, et al. (2017) Diversity of methodologies to experiment Integrated Pest Management in arable cropping systems: Analysis and reflections based on a European network. Eur J Agron 83:86-99

Melander B, Lattanzi B, Pannacci E (2015) Intelligent versus non-intelligent mechanical intra-row weed control in transplanted onion and cabbage. Crop Prot 72:1-8

Melander B, Liebman M, Davis AS, Gallandt ER, Bàrberi P, Moonen A-C, Rasmussen J, van der Weide R, Vidotto F (2017) Non-Chemical Weed Management. Pages 245-270 in Weed Research. Hoboken, NJ: John Wiley \& Sons, Inc

Miyao G, Aegerter B, Sumner D, Stewart D (2017) Sample Costs to Produce Processing Tomatoes Sub-Surface, Drip Irrigated (Sdi) in the Sacramento Valley and Northern Delta 2017. https://coststudies.ucdavis.edu/en/ current/commodity/tomatoes/ Accessed July 27, 2019.

Pérez-Ruíz M, Slaughter DC, Fathallah FA, Gliever CJ, Miller BJ (2014) Co-robotic intra-row weed control system. Biosyst Eng 126:45-55

Raja R, Slaughter DC, Fennimore SA, Nguyen TT, Vuong V, Sinha N, Tourte L, Smith RF, Siemens MC (2019a) Crop signaling: a novel crop recognition technique for robotic weed control. Biosyst Eng 187:278-291

Raja R, Slaughter DC, Fennimore SA (2019b) A novel weed and crop recognition technique for robotic weed control in a lettuce field with high weed densities. ASABE Annual International Meeting, Vol. 1 https://elibrary. asabe.org/abstract.asp?aid=50357 Accessed December 7, 2019

Raja R, Slaughter DC, Fennimore SA (2019c) Precision weed control robot for vegetable fields with high crop and weed densities. ASABE Annual International Meeting, Vol. 1 https://elibrary.asabe.org/abstract.asp? aid=50358 Accessed December 7, 2019

Rasmussen J, Griepentrog HW, Nielsen J, Henriksen CB (2012) Automated intelligent rotor tine cultivation and punch planting to improve the selectivity of mechanical intra-row weed control. Weed Res 52:327-337

Slaughter DC (2014) The biological engineer: sensing the difference between crops and weeds. Pages 71-95 in Young SL, Pierce FJ, eds. Automation: The Future of Weed Control in Cropping Systems. Dordrecht: Springer

Slaughter DC, Giles DK, Downey D (2008a) Autonomous robotic weed control systems: A review. Comput Electron Agric 61:63-78

Slaughter DC, Giles DK, Fennimore SA, Nguyen TT, Vuong V, Neilson L, Billing R, Roach JI, Vannucci B (2019) Robotic Plant Care Systems and Methods. US Patent Application Publication. Pub. No. US 2019/0104722 A1

Slaughter DC, Giles DK, Fennimore SA, Smith RF (2008b) Multispectral machine vision identification of lettuce and weed seedlings for automated weed control. Weed Technol 22:378-384

Su WH, Fennimore SA, Slaughter DC (2019) Fluorescence imaging for rapid monitoring of translocation behavior of systemic markers in snap beans for automated crop/weed discrimination. Biosyst Eng 186:156-167

Taylor AG, Salanenka YA (2012) Seed treatments: phytotoxicity amelioration and tracer uptake. Seed Sci Res 22:S86-S90

Tourte L, Smith RF, Klonsky K, De Moura R (2009) Sample costs to produce organic leaf lettuce: Central Coast Region 2009. https://coststudies.ucdavis. edu/en/archived/commodity/lettuce/ Accessed July 18, 2019

Tourte L, Smith RF, Klonsky K, Sumner D, Gutierrez C, Stewart D (2015) Sample costs to produce and harvest romaine hearts Central Coast Region 2015. https:// coststudies.ucdavis.edu/en/archived/commodity/lettuce/ Accessed July 18, 2019

Tourte L, Smith RF, Murdock J, Sumner DA (2017) Sample Costs to Produce and Harvest Iceburg Lettuce Central Coast Region 2017. https://coststudies. ucdavis.edu/en/current/commodity/lettuce/ Accessed July 18, 2019

[USDA-NASS] United States Department of Agriculture-National Agricultural Statistics Service (2019) Vegetables 2018 summary. downloads.usda.library. cornell.edu/usda-esmis/files/02870v86p/gm80j322z/5138jn50j/vegean19. pdf Accessed October 3, 2019

Van Der Weide RY, Bleeker PO, Achten VT, Lotz LA, Fogelberg F, Melander B (2008) Innovation in mechanical weed control in crop rows. Weed Res 48:215-224

Yang D, Avelar SA, Taylor AG (2018) Systemic seed treatment uptake during imbibition by corn and soybean. Crop Sci 58:2063-2070

Zahniser S, Taylor JE, Hertz T, Charlton D (2018) Farm labor markets in the United States and Mexico pose challenges for U.S. Agriculture. United States Department of Agriculture-Economic Research Service. https://www.ers.usda. gov/publications/pub-details/?pubid=90831 Accessed November 1, 2019 